\title{
The Effect of Thought Stopping Therapy on The Blood and Pulse Pressures as an Anxiety Indicator of Injections
}

\author{
Latipun dan Hevi Mulia Putri \\ University of Muhammadiyah Malang \\ lativ_un1@yahoo.com \\ Yohan Kurniawan \\ Universiti Malaysia Kelantan
}

\begin{abstract}
Injection is one of healthcare method. Injection can be used to curing and preventing, but it has negative effect such as resulting in pain, overdose and spreading of infection. It can result in anxiety. This factorial design $2 \times 2$ study investigated the effect of thought stopping therapy in reducing anxiety of injection. Participants were 40 nursing student in Malang, Indonesia. They were $18-$ 22 years old with $35-65$ score of STAI-20 form Y2. Digital sphygmomanometer, digital thermometer and respiratory rate timer were used to measuring the change of physiological scored. Kruskal Wallis analysis showed that thought stopping therapy had significant effect in reducing anxiety of injection on blood pressure $(\mathrm{p}=0.001)$ and pulse $(\mathrm{p}=0.000)$, but this effects were not significant on temperature $(\mathrm{p}=0.234)$ and respiratory rate $(\mathrm{p}=0.55)$. This implies that stopping therapy can be used to reducing anxiety of injection.
\end{abstract}

Keywords: Injection, thought stopping, anxiety, physiology.

\section{BACKGROUND}

Injection is a health procedure commonly applied for treating a patient. According to the ordinary citizen point of view in Indonesia, any treatment using injection is considered to be more effective than the oral treatment. In a global scale, the World Health Organization (2000) estimated that 12 millions of injections are made every year either for vaccines, contraception, treatments, or other purposes (Mather et al., 2008).

Injection can provide positive benefits either for preventive or curative purposes. Even in some cases, it may be considered as a medium for the most effective medical action because it can provide effects in a relatively quick time. However, this injection procedure may also have negative effects such as risks of infection spread, over-dosage and pain.

There are many people who imagine the negative effects of injection when they will take such a procedure. It is the factor that makes many people anxious if the procedure will be applied to them. Wright, Yelland, Heathcote, \& Ng (2009) report that $22 \%$ of 117 patients in The Ormeau General Practice, Southeact Queensland felt anxiety at injection. This was also experienced by 23\% of 400 tourists in Travel Health ClinicBnai Zion Medical Center Haifa, Israel (Nir, Paz, Sabo, \&Potasman, 2003. Moreover, $63.08 \%$ of the Bulgarian students at the age between 25-26 years felt worried about injection when their teeth were examined (Kirova, 2011).

Such anxiety of injection may be identified not just through the patients' acknowledgement. It is very clear that the anxiety of the patience can be identified when they face the real situation of being injected. Some signs of increasing the metabolism in a form of the enhancement the vital signs in the body, such as the increasing of the temperature, pulse, breath and blood pressure (Jenkins, 2014; Gramer, 2006). Therefore, it is clear that anxiety may affect some physiological changes of the body.

Anxiety of injection is always related to the various factors. Female subjects, neurotic personality, and traumatic experiences associated with injection the injection procedures are the risk factors for increasing the anxiety of the injection procedure for individuals. In a cognitive approach, the anxiety occurs because of an individual experiencing a cognitive distortion, thinking that exceeding injections result in negative effects that may be harmful to them. Factors of gender, personality, and traumatic experiences may reinforce individuals' anxiety of injections.

There are some experiences in the laboratory during the nursing education, the injections by peer students were resulted in some anxieties, but this anxiety did not happen in the real medication situation in the hospital or when the injection was prescribed by the medical staffs. The perception to the injector's competence also stimulates the anxious feelings for the patients, especially those have cognitive distortion.

The injector's competency is responded by an individual in a certain ways. If the injector is considered to have less competence, this may occur the individual anxiety. This competency is very important especially in terms of accuracy, pain reduction and various possibilities that may happen. In other words, the injector's competency relieved the feelings of safety to those receiving the injection. As a result, the injection receivers have more trusted to the professional injectors 
Table 1. Characteristics of subject based on gender, age, hospitalization experience, and the STAI - 20 Form Y2 score.

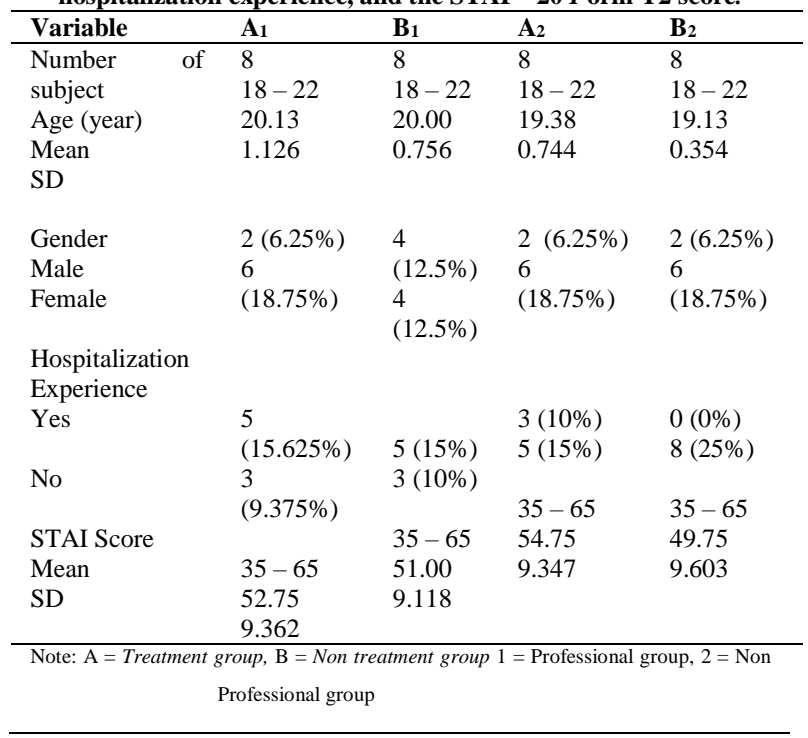

(Frydendal, Tvermyr, \&Marlén, 2012) than those considered to be less professional ones.

Anya anxiety of injection results in individual to avoid medical actions. The anxiety may continue and increase so that the individuals experience frighten of, even phobia with injection. By the study of Wright et al (2009) Southeast Queensland, 2.3\% patients that would be injected of phobia experienced with the hypodermic needles so that they always avoided the medical action.

Principally, the anxiety of injection may be reduced with a psychological therapy. A thought stopping method is one of the methods in a cognitive therapy that is often used in reducing such an anxiety. This method is applied to help individuals think more really and realistically, and reduce some cognitive distortion (Knapp \& Beck, 2008). The objective of this present research is to understand the effect of the thought stopping on lowering the blood and pulse pressures as an indicator of anxiety at injection.

\section{RESEARCH METHODOLOGY}

\section{The Experimental Design}

Two groups, the treatment and non-treatment were employed. The treatment group is the one receiving any thought stopping interventions, while the non-treatment did not receive any treatment. Each group consisted of two sub groups, where one group was injected by professional, while the other by non professional. In this study, professional is the one who has passed the competence test of nursing and has obtained a certificate of the competence test, while non professional is the one who has not joined in the competence test of nursing, namely students who are following the training of giving injections.

\section{Subject}

The research subject is offered for the third year students of Nursing Department taking the Fundamental of Nursing subject. Thirty two (32) students, aged 18-22 years $(M=19.66, S D=0.865)$ with the STAI-20 form Y2 scores between 35 of 65 participated in the experiment. The subject was randomly divided into 4 (four) groups, each consisting of 8 students. The characteristics of the subject are presented at Table 1.

\section{Instruments and Measurement Procedure}

The subject was screened using the State Trait Anxiety Inventory- 20 (STAI-20) Form Y to measure the individual's trait anxiety (Marteau \&Bekker, 1992). The STAI-20 Form $Y$ consists of 20 items, applied one week before the treatment. The reliability test showed that all the question items were reliable where the consistency coefficient is $\alpha=0.783$ (Vitasari, Wahab,

Herawan, Othman, \&Sinnadurai, 2011).

The state anxietywas made by measuring vital signs, consisting of the blood and pulse pressures. This physiological measurement lasted one minute using a digital spygmomanometer.

\section{RESEARCH PROCEDURE}

\section{Measuring the variables}

This research was done in laboratory of Nursing Department, University of Widyagama Malang, Indonesia. The data were collected twice, during pretest (one week before the thought stopping intervention) and posttest (one week after the intervention).The measurement of physiology was taken 5-10 minutes before injection.

\section{Intervention Procedure}

For the treatment group would be given the therapy of thought stopping has a four session a month. The first session was intended to explore the clients' personality. The second session is to identify and to stop any disturbing thoughts, by discussing with the clients about the disturbing thoughts, consisting of the thought characteristics (realistic or unrealistic thought) and the subject's belief in the disturbing thoughts. In the process, the clients were asked to choose one of the thoughts that they really wanted to stop and to write negative thoughts using the word "stop" and to replace it with positive one. The practice was made until the subject was able to stop their negative thought without the word "stop". The fourth session was intended to control any thought stopping automatically, it is the clients are trying to make some thought stopping by their own and repeatedly without helping from therapists. 


\section{RESULTS AND DISCUSSION}

The data were analyzed using the Mann Whitney, Wilcoxon and Kruskal Wallistests. The Mann Whitney analysis was employed to understand the differences between two unpaired groups, the Wilcoxon, between two paired groups and the Kruskal Wallis, between two or more groups.

\section{Pre-test Analysis}

The Kruskal Wallis analysis showed that there was a significant difference in the anxiety scores among the whole groups studies before the therapy was made (p>0.05). The Mann Whitney analysis, however, proven that there was no significant difference in the anxiety score among Treatment Professional, non Treatment Professional, non treatment professional and non treatmentnon professional groups before the therapy $(\mathrm{P}>0.05)$. Based on the gender and the hospitalization experience, the anxiety score during the pretest was also relatively homogenous ( $p>0.05)$. The difference in the anxiety scores during the pretest is presented in detail at Table 2

\section{Lowering of Anxiety}

The Wilcoxon analysis showed that there is a differences in the anxiety scores between the pretest and posttests at the treatment group $(\mathrm{p}<0.05)$. The pretest anxiety scores $(\mathrm{M}=6.69, \mathrm{SD}=1.306)$ are higher than the posttest ones $(\mathrm{M}=-8.72, \mathrm{SD}=8.891)$, but this is not the case for the non-treatment group ( $\mathrm{p}>0.05)$. Therefore, significant lowering of anxiety happened to the group receiving the thought stopping therapy (the treatment group).
The difference in the anxiety scores at the pretest and posttest between was not found out between professional and non professional groups.

A significant difference in the anxiety scores at the pre and posttest is also shown at the non professional group $(\mathrm{p}<0.05)$. The pretest anxiety scores $(\mathrm{M}=6.78$, $\mathrm{SD}=1.184)$ are higher than the posttest $(\mathrm{M}=-1.41$, $\mathrm{SD}=11.634)$. Therefore, the lowering of anxiety happens to either the professional-injected group or the non professional-injected group.

An analysis of the comparison of the anxiety scores between the pre and posttests is made to the treatment and non treatment groups $(\mathrm{p}<0.05)$. As a whole, the lowering of the anxiety scores at the treatment group ( $\mathrm{M}=-15.41, \mathrm{SD}=9.161)$ is higher than those at the non treatment group $(\mathrm{M}=-2.66, \mathrm{SD}=8.775)$.

Table 2. The test result of the inter-group anxiety levels before the thought stopping therapy test

\begin{tabular}{lll}
\hline \multicolumn{1}{c}{ Research Group } & \multicolumn{2}{c}{ Dependent Variable } \\
\cline { 2 - 3 } & Pressures & Pulse \\
\hline 1. The whole group,** & 1.922 & 1.731 \\
2. Treatment vs non treatment groups* & -0.797 & -0.581 \\
Treatment Professional vs Non Treatment Professional* & -1.313 & -0.924 \\
Non TreatmentProfessionalvs Non Treatment Professional* & -0.655 & -0.054 \\
3. Professional vs non professional group** & -1.984 & -0.891 \\
Treatment Professional vs Non Treatment Professional* & -0.215 & -0.054 \\
Non Treatment Professional vs Non Treatment Non Professional* & -2.510 & -1.243 \\
4. Male vs female* & -0.881 & -1.796 \\
5. Once hospitalized vs Never hospitalized* & -1.980 & -1.833 \\
\hline
\end{tabular}

Note: The whole data $\mathrm{p}>0.05$, a Treatment Professional vs Non Treatment Professional Groups vs non Treatment Professional vs Treatment Professionalgroups,

* Mann Whitney, analysis** Kruskal Wallis analysis

The Wilcoxon showed that there is a significant difference in the anxiety scores between professional groups before and after the therapy $(\mathrm{p}<0.01)$. The pretest anxiety scores $(\mathrm{M}=6.25, \mathrm{SD}=-3.63)$ are higher than the posttest ones $(\mathrm{M}=-3.63, \mathrm{SD}=10.083)$. 
Table 3. The test results of the anxiety scores between pre and posttests

\begin{tabular}{|c|c|c|}
\hline \multirow[b]{2}{*}{ Group } & \multicolumn{2}{|c|}{ Dependent Variable } \\
\hline & $\begin{array}{l}\text { Pressures } \\
\text { Blood }\end{array}$ & Pulse \\
\hline 1. Treatment Group $\mathrm{a}, \mathrm{x}$ & $-3.519 * *$ & $-3.521 * *$ \\
\hline 2. Non TreatmentGroup ${ }^{\mathrm{a}, \mathrm{x}}$ & -1.649 & -1.624 \\
\hline 3. Professional Group ${ }^{\mathrm{a}, \mathrm{x}}$ & $-3.518 * *$ & $-3.102 * *$ \\
\hline 4. Non ProfessionalGroup $\mathrm{p}^{\mathrm{a}, \mathrm{x}}$ & $-2.332^{*}$ & $-2.617 * *$ \\
\hline 5. Treatment Professional Group ${ }^{\mathrm{a}, \mathrm{x}}$ & $-2.527 *$ & $-2.536^{*}$ \\
\hline 6. Non Treatment Professional Group ${ }^{\mathrm{a}, \mathrm{x}}$ & $-2.527 *$ & $-2.530 *$ \\
\hline 7. Non TreatmentProfessionalGroup ${ }^{\mathrm{a}, \mathrm{x}}$ & $-2.524 *$ & -1.442 \\
\hline 8. Non treatmentGroupNon professional ${ }^{\mathrm{a}, \mathrm{x}}$ & -0.169 & -1.053 \\
\hline 9. Treatment $><$ Non treatment ${ }^{\mathrm{b}}$ & $-4.728 * *$ & $-4.451 * *$ \\
\hline Treatment Professional vs Non TreatmentProfessional ${ }^{\mathrm{b}}$ & $-3.368 * *$ & $-3.066^{* *}$ \\
\hline Treatment Non Professional vs Non treatment Non Professional ${ }^{\mathrm{b}}$ & $-3.294 * *$ & $-3.153 * *$ \\
\hline 10. Professional $><$ Non professional $^{\mathrm{b}}$ & -0.698 & -0.378 \\
\hline Treatment Professional vs Treatment Non Professional ${ }^{\mathrm{b}}$ & -1.107 & -0.845 \\
\hline NonTreatment Professional vs Non treatment Non Professional $^{\mathrm{b}}$ & -0.843 & -0.106 \\
\hline 11. The whole Group, y & $23.345^{* *}$ & $20.728 * *$ \\
\hline
\end{tabular}
treatment non professional vs non treatment professional groups

An analysis of the comparison of the anxiety scores between the professional and non professional groups shows that there is no difference in the anxiety scores either at the blood $(\mathrm{p}=0.491)$ or pulse pressures variables $(\mathrm{p}=0.725)$.

The analysis shows that there are differences in the pre and posttests anxiety scores in all groups. A significant differences in the anxiety scores happens to the blood $(\mathrm{p}=0.000)$ and pulse pressures variables $(\mathrm{p}=0.000)$. The analysis results of the effect of thought stopping therapy on the lowering of anxiety are shown in detail at the Table 3.

\section{DISCUSSION}

The increasing of the TTV in human body is the manifestation of the efforts made by the body to distribute oxygen into the whole parts of the body. Oxygen in the body is needed to process the oxidation in forming the energy for metabolism. When one is experiencing some anxiety, his/her energy needs is increasing. The increasing of the TTV is used to fulfill the needs for oxygen when some anxiety happens. This increase is triggered by the stimulus of the sympathetic nerve (Calder, Lawrence, \& Young, 2001). The sympathetic nerve is stimulated by some hormonal changes due to imbalance of neurotransmitter when some axiety occurs (Streeter et al, 2010).

The increasing of the TTV is marked by the increase in blood and pulse pressures. The increase in the blood and pulse pressures is the manifestation of the heart contraction increase to distribute the blood into the whole parts of the body. Human blood possesses hemoglobin used to bring oxygen. The range of the blood and pulse pressures is subjective in nature, depending on the need for oxygen that should be fulfilled (Dolbow, Farley, Kim, $\&$ Caputo, 2008). In this present research, the lowering of the blood and pulse pressures happened to the whole groups.

In this present research the difference in the anxiety scores between professional and non professional groups was also analyzed. The results of the analysis showed that there is no significant difference in the anxiety level between the two groups. It might be caused by some factors. The first factor is the researcher's inaccurate assumption that trust may be represented by a professional. But such trust and professionalism is subjective (Evans, 2008). An evaluation to injectors by one subject and the other might be different. This high subjectivity may result in different trust the subject had to

Second is familiarity factor. This factor also influences the research results. In this research, the injectors and the research subject were familiar to one another. This process may raise the subjectivity of one's evaluation. The research subject did not merely consider injector's professionalism, but also other factors the research subject knew about the injector. As a result, it is necessary to make further studies to know subjects' trust by using mediators, namely persons who are not familiar with one and another.

In this present research, the thought stopping therapy proved to give effects on lowering some anxiety at injections. This therapy is one of types of cognitive therapies that may manipulate human thoughts. Anxiety at injection is the manifestation of changes of the number of neurotransmitters in the brain due to human cognitive disorders caused by injection actions. This therapy may be used to prevent any human cognitive disorders caused by injections so that any anxiety will not happen. 
In early sessions, subjects were required to write any disturbing thoughts. Therapists asked the subjects to decide the disturbing thoughts through actions or words. The decision will be effective if it is accompanied by actions (Davis, 2008). The decision is made by saying the word "stop" when in his mind, negative thoughts about injections come. The use of the word "stop" physiologically gives instructions to the brain so that the content of GABA may be maintained at a normal limit (Nasution, 2009).

Therapists rationalized negative thoughts of injections. This rationalization is used to raise some awareness and to give knowledge to subjects that the negative thoughts may be controlled. Repetition is one of a learning process that may change individuals' behavior (Videbeck, 2008).

\section{Scope and Limitation}

This present research still possesses some limitations. Any anxiety at injections is a complex problem because it is influenced by many factors, such as the limitation in controlling confounding factors, independent exercises the subjects did, and effects of repetitions.

\section{Implications of the Research Results}

In this research, the thought stopping therapy proved to be able to low down any anxiety at injections. The results of this research may give an implication that the cognitive therapy (thought stopping) may be used to reduce one's anxiety when one should be injected. The thought stopping therapy is easy to apply and may be used independently by all people. This therapy may be utilized in the health world to make patients more cooperative in receiving any treatment. This research result proved that any anxiety may be controlled without using any medical treatments that are riskier to the human body.

\section{CONCLUSION}

The thought stopping therapy may significantly low down the blood and pulse pressures as an indicator of anxiety of injections. The lowering of anxiety significantly occurs of the treatment group. The Lowering of anxiety significantly did not happen to the professional group. The lowering of anxiety of the treatment group is higher than that of the non treatment group. The lowering of anxiety of the professional and non-professional groups is not significantly different.

\section{REFERENCE}

Calder, A. J., Lawrence, A. D., \& Young, A. W. (2001). Neurophysiology of fear and loathing. Neuroscience, 2, 352-363.

Davis, M., Elshelman, E.R., \& McKay, M. (2009). The Relaxation and Stress Reduction Workbook $6^{\text {th }}$ Ed. New York: New Harbinger Education.

Dolbow, D. R., Farley, R. S., Kim, J. K., \& Caputo, J. L. (2008). Oxygen consumption, heart rate, rating of perceived exertion, and systolic blood pressure with water treadmill walking. Journal of Aging and Physical Activity, 18, 14 23.

Evans, L. (2008). Professionalism, professionality and the development of education professionals. British Journal of Educational Studies, 56 (1), 20 - 38.

Frydendal, A.,Tvermyr, K., \&Marlén, K. (2012). Clinical management of the adult patient with dental anxiety(Thesis,Institutt for KliniskOdontologi)

Gramer, M. (2006). Social anxiety and cardiovascular responses to active coping condition. Psychology Science, 48(2), 3952.

Jenkins, W. S. (2014). Differential examination of disgust in spider, blood-injection, and contamination fear: selfreported and attention-based assessment of differences. Disertation : Louisiana State University.

Kirova, DG. (2011). Dental anxiety among dental students. Journal of International Medical Association Bulgaria, 17 (2), $137-139$.

Knapp, P., \& Beck, A.T. (2008). Cognitive therapy: foundations, conceptual models, applications and research. Revista Brasileira de Psiquiatria, 30, S54 - 64.

Marteau, T., \&Bekker, H. (1992). The development of a six item short form of the state scale of the Spielberger State Trait Anxiety Inventory (STAI). British Journal of Psychology, 31(2), 301-306.

Mathers, B. M., Degenhardt, L., Phillips, B., Wiessing, L., Hickman, M., Strathdee, S. A., ... Mattick, R. P. (2008). Global epidemiology of injecting drug use and HIV among people who inject drugs: a systematic review. The Lancet Journal, 372 (9561), 3733-3745.

Nasution, M. L. (2011). Pengaruh Thought Stopping terhadap tingkat kecemasan keluarga (Caregiver) dengan anak usia sekolah yang menjalani kemoterapi di RSUPN Dr. CiptoMangunkusumo. (Tesis, Universitas Indonesia).

Nir, Y., Paz, A., Sabo, E., \& Potasman, I. (2003). Fear of injections in young adults: prevalence and associations. American Journal Tropical Medical Hygiene, 68 (3), 341344

Streeter et al. (2010). Effects of yoga versus walking on mood, anxiety, and brain GABA levels: a randomized controlled study. The Journal of Alternative And Complementary Medicin, 16 (11), 1145-1152.

Videbeck, S.L. (2006). Psychiatric mental health nursing. Philadephia: Lippincott William \& Wilkins.

Vitasari, P., Wahab, M.N.A., Herawan, T., Othman, A.,\&Sinnadurai, S.K. (2011). Re-test of State Trait Anxiety Inventory (STAI) among engineering students in Malaysia: Reliability and validity tests. Procedia Social and Behavioral Sciences, 15, 3843 - 3848.

World Health Organization. (2000). Injection safety: Report by the secretariat 107th session. . Geneva: World Health Organization Executive Board.

Wright, S., Yelland, M., Heathcote, K., \& Ng, S.-K. (2009). Fear of needles : Nature and prevalence in general practice. Australian Family Physician, 38 (3), 172-176. 